\title{
Knowledge about heart failure in primary care: Need for strengthening of continuing medical education
}

\author{
Agnieszka Parnicka ${ }^{1}$, Barbara Wizner ${ }^{1}$, Małgorzata Fedyk-Łukasik ${ }^{1}$, \\ Adam Windak ${ }^{1,2}$, Tomasz Grodzicki ${ }^{1}$ \\ ${ }^{1}$ Department of Internal Medicine and Gerontology, \\ Jagiellonian University Medical College, Krakow, Poland \\ ${ }^{2}$ The College of Family Physicians in Poland
}

\begin{abstract}
Background: Heart failure (HF) is a common complication of cardiovascular diseases, and patients with $H F$ remain largely under the care of primary care physicians (GPS). Therefore, the goal of the study presented was to assess the GPS' knowledge of chronic HF guidelines in regards to their professional experience.
\end{abstract}

Methods and results: In 2008, during a nationwide educational project on HF management, 15 courses for GPS were conducted. Before the training, physicians filled out a standardized questionnaire about the diagnosis and treatment of HF. The answers were assessed in a three age-group of respondents: $24-39$ years $(n=142), 40-55$ years $(n=316), 56$ years and above $(n=156)$. Of 614 physicians, $97 \%$ indicated echocardiography as obligatory diagnostic procedure in HF diagnosis. The oldest GPs more frequently pointed to the role of chest X-ray $(63 \%, p<0.001)$ and electrocardiography $(32 \%, p<0.001)$ in exclusion of systolic HF. There was a significant reverse relationship between physicians' age and their declarations in prescription of angiotensin II receptor blockers ( $p=0.007$; contingency coefficient, $C_{c}=0.13$ ) and $\beta$-blockers ( $\left.p=0.01 ; C_{c}=0.12\right)$ in patients with advanced HF (NYHA III-IV), and positive relation between application of spironolactone $\left(p=0.007 ; C_{c}=0.13\right)$ and digitalis $(p<0.001$; $C_{c}=0.16$ ) in patients of NYHA class I-II. The new generation $\beta$-blockers (bisoprolol, carvedilol, nebivolol) were more frequently prescribed by the youngest physicians (respectively: $98 \%, 96 \%, 58 \%$ ) compared to the oldest group (respectively: $88 \%, 87 \%, 50 \%$; $p<0.05$ ).

Conclusions: The study revealed age of GPs to be inversely related to their knowledge of HF guidelines and potential therapeutic decisions in management of HF patients and support of the need of continuing medical education. (Cardiol J 2013; 20, 4: 356-363)

Key words: heart failure, primary care physicians, knowledge of guidelines

\section{Introduction}

Heart failure (HF) is currently one of the most common and rising chronic diseases in developed countries. Total percentage of people with $\mathrm{HF}$ reaches $0.4-2 \%$ in Europe [1] and among people over the age of 75 it exceeds 10\% [2]. In European Union countries the number of patients surpasses 15 million [3] and in Poland 1 million [4]. The study conducted in Poland in 2005 showed that most of

\footnotetext{
Address for correspondence: Prof. Tomasz Grodzicki, MD, PhD, Department of Internal Medicine and Gerontology, Jagiellonian University Medical College, ul. Śniadeckich 10, 31-531 Kraków, Poland, tel: +48 1242488 00, fax: +48 1242488 54, e-mail: tomekg@su.krakow.pl 
the patients with HF were under the care of primary care physicians (GPs) [5].

The randomized, multicentre study SHAPE (the Study group on Heart Failure Awareness and Perception in Europe), carried out in 2008, also in Poland, showed poor adherence to guideline-recommended management strategies of HF, especially in the group of internists, geriatricians and GPs [6]. Similarly, recently published data of the Polish study, assessing the knowledge of 125 GPs, demonstrated that a satisfactory adherence to Polish guidelines-management of hypertension characterized $51 \%$ GPs [7].

To our best knowledge, the relationship between a physician's age or years of professional experience has not been studied yet. Therefore, the aim of the presented study is to assess whether age of GPs is associated with their knowledge of chronic $\mathrm{HF}$ guidelines and is it related with therapeutic decision making in management of HF patients.

\section{Methods}

In 2008, a Polish nationwide education project for GPs about guideline-recommended management strategies in $\mathrm{HF}$ was conducted. It was a multicenter project, and a training program was developed in collaboration with The College of Family Physicians in Poland.

The trainings' schedule and agenda were available on the official website of the College. The project was also promoted in the educational journal of Polish GPs and in a newsletter sent periodically to GPs. Recruitment for participation in training was conducted through the website.

The courses were conducted in 15 provinces in Poland from 15 September to 30 November 2008, and the study involved 872 GPs. At the beginning of each training, participants filled out a standardized questionnaire consisting of 19 questions -5 of them related to the diagnosis and 14 to the recommendations from 2008 on the treatment of chronic HF. There were 16 single and 3 multiple choice type questions with predefined answers.

The answers were assessed according to the guidelines of European Society of Cardiology (ESC) published in 2005 [8]. The analysis was performed in three age-groups of physicians:24-39 years $(n=142)$, $40-55$ years $(\mathrm{n}=316)$ and 56 and more years old $(\mathrm{n}=156)$.

The database management and statistical analysis were performed using SAS software, version 9.2 (SAS Institute Inc, Cary, NC) licensed to the Jagiellonian University.
Descriptive statistics involved mean \pm standard deviations (SD) and percentages. Distribution of continuous variables was determined by Shapiro-Wilk test. One-way ANOVA was used for comparisons of continuous variables between the age-groups and contingency coefficient $\left(\mathrm{C}_{c}\right)$ to determine association between categorical variables.

\section{Results}

Out of 872 GPs who attended all training courses, 614 completed and returned the questionnaires $(70 \%)$. The mean age of the respondents was $48.0 \pm 11.5$ ranging from 24 to even 90 years, $76 \%$ of them were women.

\section{Heart failure diagnosis and classification}

More than $96 \%$ of GPs from each age-group indicated echocardiography as a procedure essential to diagnose HF (Table 1). The oldest physicians more frequently than the younger ones pointed to the role of chest X-ray $(63 \%, \mathrm{p}<0.001)$ and electrocardiography $(32 \%, \mathrm{p}<0.001)$ in exclusion of systolic HF. On the other hand, the younger physicians significantly more likely indicated left ventricular ejection fraction (LVEF), above $50 \%$, without mitral insufficiency as exclusion criterion (Table 1).

Only $23 \%$ of GPs recognized and declared the application of current HF classification as systolic and diastolic (with preserved LVEF). This classification has not been used by $72 \%$ of physicians, despite the knowledge of this classification. However, the New York Heart Association (NYHA) scale was used on everyday practice by almost all the GPs (94\%); only $1 \%$ of GPs did not apply any of these classifications.

\section{Heart failure pharmacotherapy}

For HF patients with NYHA class I or II and sinus rhythm, angiotensin converting enzyme inhibitors (ACE-I), angiotensin II receptor blockers (ARB), $\beta$-blockers, and diuretics were recommended by physicians from different age groups with similar frequency (Table 2). Older physicians significantly more frequently indicated spironolactone, digitalis, and calcium channel blockers as preferred drugs (Table 2).

In patients with advanced HF (NYHA class III to IV), the respondents favored diuretics, spironolactone and digitalis without significant differences between the age-groups (Table 2). Moreover, older GPs, compared to younger, declared less frequent use of ARB and $\beta$-blockers. Younger GPs were 
Table 1. Primary care physicians' opinion about heart failure diagnosis.

\begin{tabular}{|c|c|c|c|c|c|c|}
\hline & \multirow[t]{2}{*}{$\mathbf{N}$ valid } & \multicolumn{3}{|c|}{ Physicians' age $(n=614)$} & \multirow[t]{2}{*}{$\mathbf{P}$} & \multirow[t]{2}{*}{$\mathrm{C}_{\mathrm{c}}$} \\
\hline & & $\begin{array}{c}24-39 \\
(n=142)\end{array}$ & $\begin{array}{c}40-55 \\
(n=316)\end{array}$ & $\begin{aligned} & \geq 56 \\
(n & =156)\end{aligned}$ & & \\
\hline Age (mean \pm SD) & 614 & $32.9 \pm 4.5$ & $47.7 \pm 4.7$ & $62.6 \pm 6.3$ & $<0.001$ & - \\
\hline Female $(\%)$ & 610 & 81.7 & 78.2 & 65.4 & 0.004 & - \\
\hline \multicolumn{7}{|l|}{ Diagnosis of heart failure: } \\
\hline $\begin{array}{l}\text { Echocardiography is } \\
\text { obligatory }(\%)\end{array}$ & 613 & 97.9 & 96.5 & 97.4 & 0.685 & 0.035 \\
\hline \multicolumn{7}{|l|}{$\begin{array}{l}\text { Results excluding of systolic } \\
\text { heart failure: }\end{array}$} \\
\hline Chest X-ray (\%) & 591 & 34.3 & 50.5 & 62.7 & $<0.001$ & 0.195 \\
\hline $\begin{array}{l}\text { ECG without signs } \\
\text { of } \mathrm{MI}(\%)\end{array}$ & 591 & 9.5 & 13.3 & 32.0 & $<0.001$ & 0.228 \\
\hline $\begin{array}{l}\text { LVEF about } 50 \% \\
\text { with moderate } \mathrm{MVI}(\%)\end{array}$ & 591 & 37.2 & 28.2 & 34.0 & 0.138 & 0.082 \\
\hline $\begin{array}{l}\text { LVEF about } 50 \% \\
\text { without } \mathrm{MVI}(\%)\end{array}$ & 591 & 64.2 & 61.1 & 47.7 & 0.007 & 0.129 \\
\hline $\begin{array}{l}\text { Electrolytes/serum } \\
\text { creatinine monitoring } \\
\text { every } 3 \text { to } 6 \text { months }\end{array}$ & 598 & 58.3 & 61.0 & 59.1 & 0.266 & 0.112 \\
\hline
\end{tabular}

$\mathrm{C}_{\mathrm{c}}$ - contingency coefficient; $\mathrm{MI}$ - myocardial infarction; LVEF — left ventricular ejection fraction; $\mathrm{MVI}$ - mitral valve insufficiency; $\mathrm{p}$ - value for ANOVA trend or $\chi^{2}$ for table

more likely to use sartans in their patients with HF because of intolerance of ACE-I (age 24-39: 97.0\%; 40-55: 89.4\%; 56-90: 87.1\%), whereas older GPs more often administered this class of drugs as a continuation of therapy (age 24-39: 22.0\%; 40-55: 29.9\%; 56-90: 36.7\%).

Among ACE-I recommended by the ESC guidelines were enalapril, captopril and lisinopril. The proper recommended dose of enalapril (10 mg twice a day) was indicated by $17.0 \%$ of GPs at age $24-39$; $32.1 \%$ at age $40-55 ; 13.7 \%$ at age $56-90(\mathrm{p}=0.016)$. The target dose of captopril (25-50 mg three times a day) indicated $13.4 \%$ at age $24-39 ; 21.5 \%$ at age $40-55$ and $5.3 \%$ at age 56-90. Lisinopril (5-20 mg twice a day) had been chosen in a optimal dose by $13.6 \%$ GPs aged $24-39,24.4 \%$ aged $40-55$ and $9.9 \%$ aged 56-90. Use of maximal guideline-recommended doses of ACE-I in HF patients declared $41.1 \%$ of young, $37.1 \%$ of middle-aged and $29.6 \%$ of older GPs (Table 3). In general, more than half of the youngest GPs and approximately $78 \%$ GPs from the oldest group adjusted dosage of ACE-I according to HF severity (Table 3 ).

Declared use of $\beta$-blockers, recommended by the guidelines inversely correlated with the age of the respondents. The percentage (respectively for three age categories from the youngest to the oldest) was for: bisoprolol: $97.9 \%$; $93.2 \%$; 88.1\%; $\mathrm{p}=0.005$; carvedilol: $95.7 \%$; $91.9 \%$; 87.4\%; $\mathrm{p}=0.036$; metoprolol: $90.1 \% ; 89.6 \% ; 84.1 \%$; $\mathrm{p}=0.17$ and fro nebivolol: $58.2 \% ; 44.3 \% ; 50.3 \%$; $\mathrm{p}=0.023$. Atenolol has been indicated by $15.2 \%$ of the oldest GPs, $13.0 \%$ of middle-aged and $2.1 \%$ of the youngest ones $(\mathrm{p}<0.001)$, whereas propranolol was used respectively by $6.6 \%, 5.7 \%$ and $1.4 \%$ GPs $(\mathrm{p}=0.077)$. As for the maximum recommended doses of $\beta$-blockers GPs most often pointed to: bisoprolol $10 \mathrm{mg}$ daily, carvedilol $2 \times 25 \mathrm{mg}$ per day, metoprolol $200 \mathrm{mg}$ and nebivolol $10 \mathrm{mg}$ per day. The younger GPs significantly more frequently indicated the proper target doses of the $\beta$-blockers than the older (Fig. 1). Most older GPs declared to adjust the dose of $\beta$-blockers according to the severity of $\mathrm{HF}$ and blood pressure level, while the youngest GPs more frequently declared use of maximum doses of $\beta$-blockers (Table 3 ).

Almost all of the respondents $(95.7 \%)$ recommended diuretics in patients with fluid retention and up to $43.0 \%$ of GPs used them in all patients with $\mathrm{HF}$, more frequently middle-aged physicians $(40.1 \%)$ and older physicians (59.0\%) compared with the young ones $(29.8 \%$, $\mathrm{p}<0.001)$. Diuretics, as the first drug for the treatment of HF, were chosen by $46.9 \%$ of GPs at age $56-90,33.7 \%$ of GPs at age $40-55$, and by $17.9 \%$ of the youngest GPs $(p<0.001)$. The physicians usually started treatment with low doses of loop diuretics (79.0\%) or low doses 

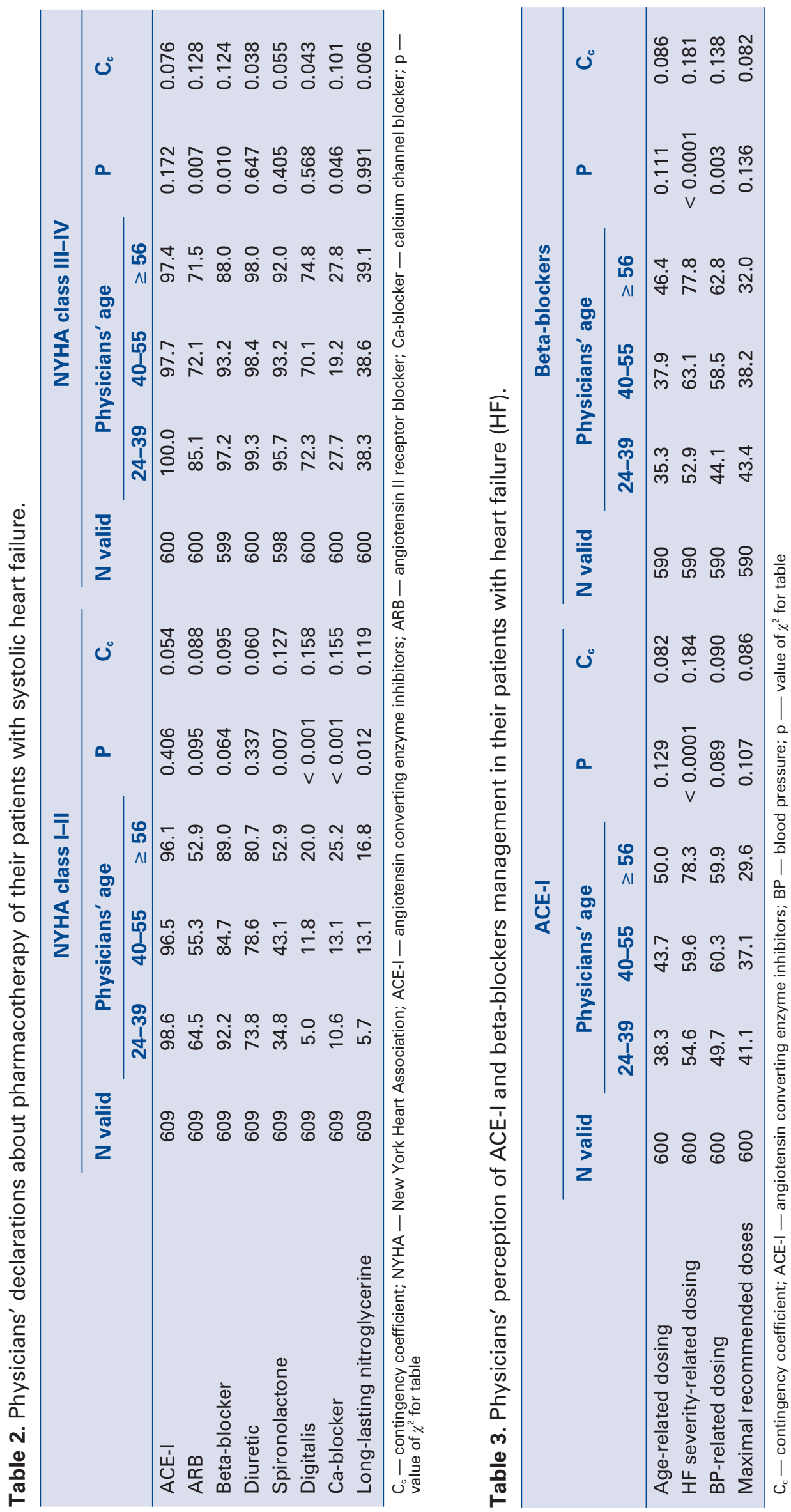


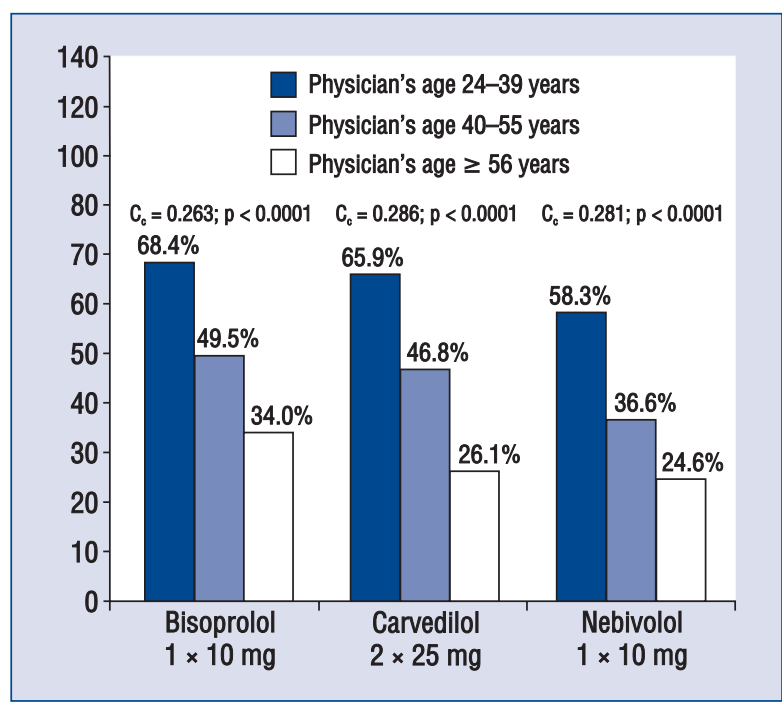

Figure 1. Physicians' awareness of $\beta$-blockers' recommended doses in management of heart failure patients; $\mathrm{C}_{\mathrm{c}}$ - contingency coefficient. of thiazide diuretics $(78.2 \%)$, and there were no significant differences in age-group comparisons.

The respondents most often declared $\beta$-blockers, ACE-I and sartans as drugs with potential to prolong the life of patients with HF (Table 4). The younger GPs more often recommended digitalis as the drug reducing $\mathrm{HF}$ symptoms, whereas the older GPs more often believed that digitalis can improve prognosis (Table 4). About half of the surveyed GPs had a difficulty in defining the role of calcium channel blockers in the treatment of HF. Apart from that, $15 \%$ of the oldest GPs expected that long-lasting nitroglycerine will improve prognosis of patients with HF (Table 4).

\section{Discussion}

Our study indicated generational differences among Polish GPs in approach to the existing guideline recommendations on $\mathrm{HF}$ diagnosis and

Table 4. Physicians' perception of expected results of pharmacotherapy in heart failure (HF).

\begin{tabular}{|c|c|c|c|c|c|c|c|}
\hline & \multirow{2}{*}{$\begin{array}{l}\text { Expected } \\
\text { results in HF }\end{array}$} & \multirow[t]{2}{*}{ N valid } & \multicolumn{3}{|c|}{ Physicians' age } & \multirow[t]{2}{*}{$\mathbf{P}$} & \multirow[t]{2}{*}{$\mathrm{C}_{\mathrm{c}}$} \\
\hline & & & 24-39 & $40-55$ & $\geq 56$ & & \\
\hline \multirow[t]{3}{*}{ ACE-I } & Symptoms & 573 & 73.7 & 78.6 & 71.2 & 0.202 & 0.075 \\
\hline & Prognosis & 573 & 94.9 & 85.2 & 79.5 & $<0.001$ & 0.157 \\
\hline & Indecision & 573 & 0.0 & 1.7 & 2.1 & 0.269 & 0.068 \\
\hline \multirow[t]{3}{*}{ ARB } & Symptoms & 554 & 67.2 & 70.4 & 59.6 & 0.086 & 0.094 \\
\hline & Prognosis & 554 & 80.6 & 64.8 & 65.4 & 0.003 & 0.143 \\
\hline & Indecision & 554 & 3.7 & 7.8 & 9.6 & 0.160 & 0.081 \\
\hline \multirow[t]{3}{*}{ Beta-blockers } & Symptoms & 568 & 66.9 & 71.5 & 63.9 & 0.247 & 0.070 \\
\hline & Prognosis & 568 & 90.4 & 81.3 & 70.8 & 0.0002 & 0.173 \\
\hline & Indecision & 568 & 0.7 & 3.8 & 4.2 & 0.175 & 0.078 \\
\hline \multirow[t]{3}{*}{ Diuretics } & Symptoms & 575 & 97.0 & 95.9 & 93.2 & 0.256 & 0.069 \\
\hline & Prognosis & 575 & 16.3 & 26.5 & 34.3 & 0.003 & 0.142 \\
\hline & Indecision & 575 & 0.0 & 1.0 & 0.0 & 0.237 & 0.071 \\
\hline \multirow[t]{3}{*}{ Spironolactone } & Symptoms & 565 & 77.2 & 85.0 & 81.7 & 0.141 & 0.083 \\
\hline & Prognosis & 565 & 59.6 & 55.1 & 47.2 & 0.107 & 0.089 \\
\hline & Indecision & 565 & 0.7 & 2.8 & 2.8 & 0.377 & 0.059 \\
\hline \multirow[t]{3}{*}{ Digitalis } & Symptoms & 556 & 92.5 & 91.6 & 83.3 & 0.016 & 0.121 \\
\hline & Prognosis & 556 & 3.8 & 8.1 & 15.9 & 0.002 & 0.151 \\
\hline & Indecision & 555 & 6.1 & 7.0 & 8.7 & 0.694 & 0.036 \\
\hline \multirow[t]{3}{*}{ Ca-blockers } & Symptoms & 486 & 41.7 & 40.4 & 38.8 & 0.904 & 0.020 \\
\hline & Prognosis & 486 & 15.0 & 13.1 & 27.3 & 0.002 & 0.156 \\
\hline & Indecision & 486 & 51.7 & 53.9 & 42.2 & 0.102 & 0.096 \\
\hline \multirow[t]{3}{*}{ Long-lasting nitroglycerine } & Symptoms & 533 & 70.5 & 65.7 & 57.1 & 0.068 & 0.100 \\
\hline & Prognosis & 533 & 3.9 & 8.5 & 15.0 & 0.006 & 0.137 \\
\hline & Indecision & 534 & 28.7 & 29.0 & 34.6 & 0.468 & 0.053 \\
\hline
\end{tabular}

$\mathrm{C}_{\mathrm{c}}$ — contingency coefficient; ACE-I — angiotensin converting enzyme inhibitors; ARB — angiotensin II receptor blocker; Ca-blocker — calcium channel blocker; $\mathrm{p}$ - value of $\chi^{2}$ for table 
treatment. At the time, the younger family physicians demonstrated better knowledge and adherence to ESC recommendations than the older ones.

Echocardiography criteria of diagnosis HF were frequently more indicated by younger physicians, while the oldest physicians were more likely to base their diagnoses on chest X-ray and electrocardiography results. In the IMPROVEMENT project (1999-2000), the first large study assessing HF patients management, only $18 \%$ of GPs indicated echocardiography as a necessary diagnostic procedure in HF [9]. Similarly, in a European Heart Failure Study (EHFS) I and II, conducted from 2000 to 2001 in 24 European countries, it was found that in some centers cardiac ultrasound was performed in $20-30 \%$ patients with suspected or diagnosed HF, and the average rate of echocardiography was $58 \%$ [10]. Our previously published data has shown that approximately $50 \%$ of $\mathrm{HF}$ patients in primary settings were not examined by echocardiography [11].

More than 10 years after the IMPROVEMENT study, our results show that $96 \%$ of GPs are aware of the role of echocardiography in the diagnostic process of HF. However, almost half of the respondents (mainly older GPs) incorrectly exclude HF on the basis of normal cardiac size in patients' chest $\mathrm{X}$-ray, as normal results of radiological examination of the chest are present in $1 / 3$ of patients with $\mathrm{HF}$, such as with preserved left ventricular function or in restrictive cardiomyopathy [12]. In recently published Italian study from 2011, 1078 GPs under the age of 40 were the group which could choose the most accurate diagnoses and treatment of cardiovascular diseases [13].

We also demonstrated that treatment strategies declared by younger doctors are more consistent with ESC guidelines. Physicians' awareness and their compliance with guideline-recommended strategies of HF pharmacotherapy has significantly improved within the last 10 years. Beginning from the aforementioned IMPROVEMENT study, ACE-I were used only in $65 \%$ of patients with HF and $\beta$-blockers in $34 \%$ of them and generally their dosage was insufficient [9-14]. The study EHFS I and II revealed that among patients with suspected or previously diagnosed HF, ACE-I were used only in $62 \%$ and $\beta$-blockers only in $37 \%$ of the patients [10]. In the same study $90 \%$ of patients with LVEF below $40 \%$ were receiving ACE-I, but $\beta$-blockers were used only in $49 \%$ of them.

In our previously published data from the POLKARD study, ACE-I were taken by $81.0 \%$ and $\beta$-blockers by $68.3 \%$ of HF patients treated by GPs [11]. Based on physicians' declaration, presented in this study, the GPs awareness of HF pharmacotherapy and their compliance with guidelines seems to improve systematically.

The SHAPE study has shown that $62 \%$ GPs in Poland (in comparison to $42 \%$ GPs in Europe) declared to prescribe ACE-I in patients with HF [6]. In comparison, $78 \%$ of cardiologists and $79 \%$ of internists and geriatricians in Poland declared to use ACE-I in over $90 \%$ of patients with HF [6].

A cross-sectional analysis that was performed with the data of $167 \mathrm{HF}$ cases with documented left ventricular systolic dysfunction, enrolled in $37 \mathrm{GP}$ practices in Germany showed that the proportion of target doses reached for ACE-I/sartan was $16 \%$ and for $\beta$-blockers only $8 \%$ [15]. When adjusted for relative contraindications, the percentage of target doses increased to $49 \%$ and $46 \%$, respectively. These data are comparable with our physicians' declarations in regards to use of maximal doses of the $\beta$-blocker, but maximal doses, both of ACE-I and $\beta$-blockers, were more likely used by younger physicians than the older.

In retrospective cohort study performed in 163 GPs in Great Britain (2001-2006), on 9311 HF patients only $36.6 \%$ were prescribed a $\beta$-blocker and $68 \%$ of them had a $\beta$-blocker currently recommended in ESC guidelines [16]. In our study, most physicians declared the use of guideline-recommended $\beta$-blockers, however up to $15 \%$ of physicians (mainly older GPs) continue to prescribe older class agents.

High position among the drugs recommended by GPs took diuretics. As many as $80.7 \%$ of older physicians declared to prescribe these drugs already in NYHA class I and II. The MAHLER study (Medical Management of Chronic Heart Failure in Europe and its Related Costs) assessed the treatment of patients by the randomly selected European cardiologists. In this study diuretics were most commonly prescribed and $79 \%$ of patients with HF, mainly class NYHA II and III, were receiving them [17].

In comparison to guidelines given by European and Polish Society of Cardiology, our study showed that GPs declared to prescribe spironolactone very often in HF cases. Half of older GPs declared the use of spironolactone in HF classified as NYHA I and II, while it should be limited in this stage to postinfarctial HF patients only. Earlier Polish study (2004, PolKARD-SPOK) revealed that $21.9 \%$ patients with HF in class NYHA II-IV were treated with spironolactone [18]. It is possible that within a few years between these two studies the GPs' awareness increased. However, we cannot compare 
these results because of the significant differences in study protocols.

Use of digitalis was declared in our study by $5 \%$ of the youngest and $20 \%$ of the oldest GPs for mild and moderate HF patients (NYHA class I-II). The ESC recommendations (from 2005) said unequivocally that digitalis in this group of patients should be used primarily in the case of co-occurrence of atrial fibrillation $(\mathrm{AF})$. We could not verify the indications for digitalis, however epidemiologic data shows that the prevalence of AF in HF population is $5-10 \%$ in NYHA class I, $25 \%$ in classes II-III, $50 \%$ in class IV [19-21]. These results suggest that our senior physicians are more likely used to the older agents, such as diuretics and digoxin, also in HF patients in NYHA class I and II.

In 2011, the study results of 25,00 family GPs in Germany were published. The physicians filled out questionnaires about the HF diagnoses and therapies in their medical practices [22]. Of all the physicians surveyed, $40 \%$ presented acceptable knowledge about the guidelines of cardiovascular diseases [22], however, only $24 \%$ of physicians correctly answered the question about the treatment of patients with $\mathrm{HF}$ in accordance with the current recommendations [22].

Within last several years the quality of care for patients with HF has significantly improved and the percentage of patients treated in accordance with current standards has increased [9-11]. To keep this beneficial process it seems important to continue educational programs among primary care physicians. Wide accessibility of the specially prepared educational materials based on the guideline recommendations, including knowledge transformation to more affordable and unequivocal communication seems to be crucial in improving physicians' awareness and perceptions of the guidelines. Over the past two decades the Canadian experiences with implementation of the Canadian Hypertension Education Program (CHEP) has fully confirmed such an approach [23, 24].

\section{Limitations of the study}

Our study should be interpreted within the context of its possible limitations. The data obtained from GPs, relating to the management of patients with HF, was based solely on their declarations in the structured questionnaire. Therefore, the results of this study cannot be directly compared with studies targeted at evaluation of diagnostic and therapeutic procedure in real practice.

Our questionnaire was conducted among participants in training sessions, so by definition it was not a representative sample of GPs in Poland.
However, the nationwide scope of the study and a large number of physicians surveyed makes the study a valuable source of information about knowledge of current $\mathrm{HF}$ guidelines.

\section{Conclusions}

Primary care physicians' awareness of HF recommendations increases, however our study indicated some discrepancies in guidelines knowledge between younger and older physicians. Various educational activities focusing on the knowledge translation might be helpful in improving quality of care for patients with HF.

\section{Conflicts of interests: none declared}

\section{References}

1. Mosterd A, Hoes AW, de Bruyne MC et al. Prevalence of heart failure and left ventricular dysfunction in the general population. Eur Heart J, 1999; 20: 447-455.

2. Kannel W, Ho K, Thom T. Changing epidemiological features of cardiac failure. Br Heart J, 1994; 72: S3-S9.

3. Cleland J, Khand A, Clark A. The heart failure epidemic: Exactly how big is it? Eur Heart J, 2001; 22: 623-626.

4. Karasek D, Kubica A, Sinkiewicz W, Błażejewski J, Bujak R. Epidemia niewydolności serca — problem zdrowotny i społeczny starzejących się społeczeństw Polski i Europy. Folia Cardiologica Excerpta, 2008; 3: 242-248.

5. Wierzchowiecki M, Poprawski K, Nowicka A et al. What primary care physicians know about diagnosis and treatment of chronic heart failure. (in Polish) Kardiol Pol, 2005; 62: 218-228.

6. Remme WJ, McMurray JJ, Hobbs FD et al. Awareness and perception of heart failure among European cardiologists, internists, geriatricians, and primary care physicians; SHAPE Study Group. Eur Heart J, 2008; 29: 1739-1752.

7. Windak A, Gryglewska B, Tomasik T, Narkiewicz K, Grodzicki T. Awareness of hypertension guidelines in primary healthcare in Poland. Blood Press, 2007; 16: 320-327.

8. Swedberg K, Cleland J, Dargie H et al. Guidelines for the diagnosis and treatment of chronic heart failure: Executive summary (update 2005): The Task Force for the Diagnosis and Treatment of Chronic Heart Failure of the European Society of Cardiology. Eur Heart J, 2005; 26: 1115-1140.

9. Cleland JG, Cohen-Solal A, Aguilar JC et al. IMPROVEMENT of Heart Failure Programme Committees and Investigators. Improvement programme in evaluation and management; Study Group on Diagnosis of the Working Group on Heart Failure of The European Society of Cardiology. Management of heart failure in primary care (the IMPROVEMENT of Heart Failure Programme): An international survey. Lancet, 2002; 360: 1631-1639.

10. Komajda M. How well are we implementing evidence-based care? Eur J Heart Fail, 2009; 8 (suppl. 1): i39-i44.

11. Fedyk-Łukasik M, Zdrojewski T, Wizner B et al. Treatment of heart failure: the National Programme for Prevention and Treatment of Cardiovascular Diseases for 2003-2005: POLKARD. (in Polish) Folia Cardiol Excerpta, 2008; 3: 149-158. 
12. Korewicki J, Leszek P, Kopacz M. Epidemiology and management of heart failure. In: Dubiel J, Korewicki J, Grodzicki T eds. Heart failure. (in Polish) Via Medica, Gdansk 2004: 2-18.

13. Tocci G, Ferrucci A, Guida P et al. Impact of physicians' age on the clinical management of global cardiovascular risk: analysis of the results of the Evaluation of Final Feasible Effect of Control Training and Ultra Sensitisation Educational Programme. Int J Clin Pract, 2011; 65: 649-657.

14. Zieliński T, Piotrowski W, Wilkins A et al. The most common methods of pharmacotherapy of chronic heart failure in a public hospital in Poland. Nationwide multicenter retrospective study. Congress of the Polish Cardiac Society in 2003, Warsaw.

15. Peters-Klimm F, Müller-Tasch T, Schellberg D et al. Guideline adherence for pharmacotherapy of chronic systolic heart failure in general practice: a closer look on evidence-based therapy. Clin Res Cardiol, 2008; 97: 244-252.

16. Calvert M, Shankar A, McManus R, Freemantle R. Evaluation of the management of heart failure in primary care. Family Practice, 2009; 26: 145-153.

17. Komajda M, Lapuerta P, Hermans $\mathrm{N}$ et al. Adherence to guidelines is a predictor of outcome in chronic heart failure: The MAHLER survey. Eur Heart J, 2005; 26: 1653-1659.

18. Pietrasik A, Starczewska M, Nita K, Szulczyk R, Filipiak KJ, Opolski G. Standard of cardiac care in the primary prevention of diseases of the cardiovascular system in an outpatients: POLKARD-SPOK. (in Polish) Choroby Serca i Naczyń, 2004; 1: 1-9.

19. Hoppe UC. Resynchronization therapy in the context of atrial fibrillation: benefits and limitations. J Interv Card Electrophysiol, 2007; 18: 225-232.

20. Dickstein K, Vardas PE, Auricchio A 2010 Focused Update of ESC Guidelines on device therapy in heart failure: an update of the $2008 \mathrm{ESC}$ Guidelines for the diagnosis and treatment of acute and chronic heart failure and the 2007 ESC Guidelines for cardiac and resynchronization therapy. Developed with the special contribution of the Heart Failure Association and the European Heart Rhythm Association. Europace, 2010; 12: 1526-1536.

21. Daubert JC. Introduction to atrial fibrillation and heart failure: A mutually noxious association. Europace, 2004; 5: S1-S4.

22. Karbach U, Schubert I, Hagemeister J, Ernstmann N, Pfaff H, Höpp HW. Physicians' knowledge of and compliance with guidelines: An exploratory study in cardiovascular diseases. Dtsch Arztebl Int, 2011; 108: 61-69.

23. Drouin D, Campbell NR, Kaczorowski J. Implementation of recommendations on hypertension: The Canadian Hypertension Education Program. Can J Cardiol, 2006; 22: 595-598.

24. McAlister F, Wilkins K, Joffres M, Leenne F et al. Changes in the rates of awareness, treatment and control of hypertension in Canada over the past two decades. CMAJ, 2011; 183: 1007-1013. 